\title{
Towards Climate Responsive Building Design: Bio-Climatic Design Features of Residential Building Typologies in the Warm-Humid Climate of Ghana
}

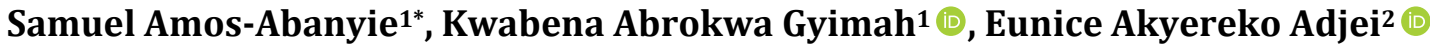 \\ ${ }^{1}$ Department of Architecture, Kwame Nkrumah University of Science and Technology, Kumasi, Ghana \\ ${ }^{2}$ Department of Mechanical Engineering, Kwame Nkrumah University of Science and Technology, Kumasi, Ghana \\ Email: ${ }^{*}$ s.a.abanyie@gmail.com
}

How to cite this paper: Amos-Abanyie, S., Gyimah, K.A. and Adjei, E.A. (2021) Towards Climate Responsive Building Design: Bio-Climatic Design Features of Residential Building Typologies in the Warm-Humid Climate of Ghana. Journal of Building Construction and Planning Research, 9, 170-187. https://doi.org/10.4236/jbcpr.2021.92012

Received: February 8, 2021

Accepted: June 13, 2021

Published: June 16, 2021

Copyright $\odot 2021$ by author(s) and Scientific Research Publishing Inc. This work is licensed under the Creative Commons Attribution International License (CC BY 4.0).

http://creativecommons.org/licenses/by/4.0/

(c) (i) Open Access

\begin{abstract}
Climatic considerations in the architectural design of most contemporary buildings have not been strictly adhered to by building design and construction professionals in the last few decades in the developing world, with users being denied the inevitable interactions with the natural surroundings offered by climate. The situation leads to utilization of energy-based equipment such as air conditioner that is environmentally unsustainable. The study aimed to evaluate the bioclimatic design features of residential building typologies and to identify features that can enhance the environmental responsiveness of buildings. This study adopted the Mahoney Tables to undertake a climatic analysis to develop appropriate design guidelines for the climate context. The developed design guidelines were then used to evaluate the bio-climatic design features of a sampled number of residential building types. The study revealed that features of the buildings reflect the recommended design guidelines, but to varied extents among the building typologies that were studied. Occupants generally find their spaces unsatisfactory primarily as a result of the experience of hot discomfort. The findings are expected to engender a renewed interest in the design of buildings in response to prevailing climatic conditions to reduce reliance on energy use and to serve as a useful reference for contemporary architectural design practice and education.
\end{abstract}

\section{Keywords}

Bio-Climatic Design, Sustainability, Mahoney Tables, Climate Responsive Design, Architectural Design 


\section{Introduction}

In the search for efficient shelter that provides comfort in an uncomfortable and changing climate, man has since ancient times adapted dwellings to the climate of a place. During the 1970s energy crisis, passive technologies that employ the use of natural energies to reduce the use of non-renewable energy to run buildings were developed [1]. For over 45 years, the energy crisis persists in many developing countries, and the deployment of passive technologies is still very low.

It is widely recognized by the global scientific community that energy consumption from non-renewable sources, such as oil or coal, is responsible for producing large quantities of Greenhouse Gases (GHG's), particularly $\mathrm{CO}_{2}$, which is largely responsible for global warming [2]. Moreover, Ganem [1] assert that the industrial revolution led to the architectural modernist movement, in which, emphasis was placed on the efficiency of the form-function concept, with the incorporation of artificial ventilation and lighting devices and auxiliaries. Regarding the principles of sustainability, the use of conventional mechanical systems to attain acceptable comfort levels was questioned by [3] in fragile economies of developing countries.

Traditional buildings in the southern part of Ghana which is a predominantly warm-humid environment are developed with three notable characteristics: 1) outward-looking terraces and open courtyards; 2 ) steeply pitched roof with wide overhangs; 3) large and fully openable windows [4]. The outward-looking terraces and open courtyards making up approximately $50 \%$ of the total floor area which serves as space for outdoor activities were an important space for typically extended families. The steeply pitched roof with wide overhang provides shade and protects buildings from rain. The large windows allowed efficient air movement for natural ventilation. The design of the traditional buildings was predominantly low rise with shallow plan buildings to allow vitiated air to be easily exhausted to the outside [5].

The bulk of the housing stock of Ghana in cities such as Accra and Kumasi are developed in the form of single-family houses on residential plots [6]. Most of the housing stock have adopted temperate style glass-clad buildings into the architectural character that exacerbates the uncomfortable conditions experienced in buildings [7]. Moreover, the windows of most of the new houses are not shaded, resulting in easy penetration of the sun rays into living spaces. As a result, spaces in buildings assume very high temperatures without the use of an air-conditioner. Consequently, hot micro-climate is induced in dense areas of cities which in effect discourages the use of natural ventilation because the buildings lack free movement of air. Natural ventilation has been replaced by air conditioning in the name of "modernity". The above contributes to high energy consumption in buildings.

There is an urgent need to design buildings to reduce energy consumption because of the increasing cost of energy in Ghana. The current building design practice in Ghana necessitates the development of a guide that can help build 
design professionals with the best design parameters for achieving a safe and sustainable environment for the warm humid climate of Ghana. A number of studies have been carried out to develop climatic responsive building design guide for specified regions [8] [9] [10] [11]. Koranteng et al. [12] sought to find out among old or new educational and administrative buildings which were constructed based on climatic design principles of the warm and humid climate to make them thermally comfortable. Consequently, this study aimed to evaluate how selected residential building typologies conform to the requirements of the bio-climatic design features of the warm-humid climate of Ghana. The studied residential buildings were selected to be able to compare the level of conformity among building that were designed by building design professionals and ones that were not. Within this context, the socio-economic and cultural needs of the occupants can be met through the provision of an environmentally safe building that reduces energy consumption in buildings for the warm-humid climate of Ghana.

\subsection{Climate of Kumasi}

Kumasi is in the tropical humid forest zone of the middle belt of Ghana and has a warm-humid climatic condition. Furthermore, the Kumasi Metropolitan Assembly as cited in [13] lies at an altitude of $250-350 \mathrm{~m}$ above sea level with an average humidity in the range of $60 \%$ to $84 \%$ depending on the season. Meteorological records from the Ghana Meteorological Agency have it that, the daily average minimum and maximum temperatures of Kumasi are $21.5^{\circ} \mathrm{C}$ and $30.7^{\circ} \mathrm{C}$ respectively. Kumasi experiences two rainy seasons: March to July and September to October, with an average total rainfall of $107.9 \mathrm{~mm}$ [13]. Table 1 presents the Mean monthly climatic data of Kumasi based on 2007 to 2016 data from the Ghana Meteorological Agency.

\subsection{Bio-Climatic Design Features for Buildings in the Warm-Humid Climate}

Bio-climatic architecture relates to the design of buildings in harmony with the environment to as much as possible achieve high energy efficiency, whilst adapting the building to the local climatic conditions, techniques and materials

Table 1. Mean monthly climatic data of Kumasi.

\begin{tabular}{cccccccccccccc}
\hline & & Jan & Feb & Mar & Apr & May & Jun & Jul & Aug & Sep & Oct & Nov & Dec \\
\hline $\begin{array}{c}\text { Dry Bulb } \\
\begin{array}{c}\text { Temperature } \\
\left({ }^{\circ} \mathrm{C}\right)\end{array}\end{array}$ & max & 33.3 & 34.0 & 33.6 & 33.0 & 32.1 & 30.5 & 29.1 & 28.5 & 29.7 & 31.2 & 32.2 & 32.4 \\
\hline $\begin{array}{c}\text { Relative } \\
\text { Humidity }\end{array}$ & 21.4 & 22.8 & 23.0 & 23.0 & 22.9 & 22.5 & 21.9 & 21.8 & 22.1 & 22.1 & 22.6 & 22.2 \\
$(\%)$ & $\operatorname{man}$ & 11.9 & 11.2 & 10.6 & 10.0 & 9.2 & 8.0 & 7.2 & 6.7 & 7.6 & 9.1 & 9.6 & 10.1 \\
\hline & average & 50.2 & 90.6 & 93.0 & 94.4 & 95.3 & 95.8 & 95.7 & 95.2 & 96.6 & 96.8 & 95.9 & 93.4 \\
\hline Rainfall $(\mathrm{mm})$ & 29.9 & 76.9 & 112.0 & 146.1 & 163.4 & 247.9 & 133.4 & 60.7 & 189.4 & 169.4 & 56.5 & 25.7
\end{tabular}


available to reduce the reliance on mechanical systems for thermal comfort [14]. Bioclimatic architecture creates an environment with satisfactory comfort levels by establishing an adaptive balanced relationship between the inner and the outer space [3]. According to [3], when there is a large difference between the air-conditioned environment and the outdoor environment, the discomfort felt by the occupants may be very high. Some documented bio-climatic design techniques meant to achieve the climatie responsible building design for the warm-humid climatic conditions in general are discussed in the following paragraphs.

Gut and Ackerknecht [15] identified design objectives for the warm-humid climate such as: 1) storing as little heat as possible in the structure in order not to cause undesirable re-radiation of heat at night; 2) continuously promoting efficient ventilation; 3) preventing radiant heat entering spaces during daytime by having the appropriate design features to do so; and 4) providing protection from the rain.

In warm-humid climate zone, orienting a building to exclude excessive solar radiation should be a major consideration of any designer [5]. Lorraine [16] and [17] recommended that, openings leading to activity zones are best placed facing the north and south and towards the prevailing wind direction. Thus, the best orientation for protection from the sun is along the east-west axis [15] and [18]. Lorraine [16] points out that orientation is directly linked with possible solar ingress, the prevailing wind direction and daylighting and therefore every facade of a building must be treated in different ways. Watson and Labs [19] claimed that a building can be made more energy-efficient if it is planned according to solar orientation and prevailing wind direction. A building may also be oriented considering factors such as daylighting, views, access, noise exclusion and privacy [16] and [20].

Among the various bioclimatic design techniques, shading which is the method of blocking or minimising the effects of solar ingress on the internal spaces of buildings is considered to be the most important and effective technique [21] [22] [23]. Since it is inevitable to prevent penetration of the sun's rays and heat through building elements such as roofs, walls and windows into the interior spaces, some techniques must be introduced to provide shading of the building elements [21] [23] [24]. Kamal [21] [22] and [23] outlines the use of recesses, static or moveable blinds or louvres on the exterior of the building envelope; and permanent or transient shading by surrounding buildings, screens or vegetation, deep verandas; wide overhangs and covered passages as effective methods of shading a building from the effects of direct solar radiation.

Air movement is induced by either pressure difference or temperature difference and hence the creation of differences in air density to cause air to flow from one point of a building to another [25] [26] [27]. Raydan and Melki [20] explain that the movement of air within a space accelerates convective and evaporative cooling rates, thus inducing physiological cooling effect. Air movement also carries away exhaust gases, odour, mould spores, pollutants, and microbial reser- 
voirs which imparts indoor air quality [26]. Gut and Ackerknecht [25] stipulate that in dense settlements, it is difficult to provide privacy as well as allowing the free flow of air. Gut and Ackerknecht [15] and [17] observed that, buildings elevated above the ground on stilts are better ventilated. Eusebius [10] further recommended that rooms should have a single-banking configuration with windows to ensure cross ventilation. In instances where the double-banking configuration is employed, temporary cross ventilation is achieved and ensured when the room height is greater than $2.75 \mathrm{~m}$.

Eusebius [10] states that building skin for warm-humid climates should be made of materials of low thermal capacity. Due to the relatively narrow diurnal temperature fluctuation of the warm-humid climate of Kumasi, it is not possible to achieve significant cooling by utilization of the thermodynamic properties of building components. Depending on the diurnal temperature differences, a reduction of the daytime indoor temperature by $0.7^{\circ} \mathrm{C}-3.0^{\circ} \mathrm{C}$ may be possible, with a time lag of about 2 to 5 hours [28]. Oppong and Badu [29] identified that the most extensively used materials for building walls in the warm-humid regions of Ghana are cement-sand blocks and corrugated metal sheets for roofing.

The form and configurations of buildings in the warm-humid region are influenced by ventilation and the path of the sun and the prevailing wind direction. Givoni [30] points out that a spread-out building layout with openable windows is more appropriate for regions with hot-humid conditions and has a good potential for cross-ventilation, especially because the vast majority of people cannot afford to buy air conditioners. Furthermore, [15] highlights the fact that in warm-humid climates, spread-out settlements with a grid-iron pattern and building forms with large surface areas are preferred to compact buildings.

Eusebius [10] recommends that all buildings should be in north-south orientation and rectangular to reduce the exposure to the sun. By this, only a small area of the building will be exposed to solar radiation, thus creating comfortable interior conditions for occupancy. Szokolay [31], alludes that aspect ratio which is the length of a building in relation to the width has a great influence on the thermal performance of a building. Szokolay [31] further recommended an aspect ratio of 1:1.3 to 2.0 for elongated buildings depending on the climate, whereas [19] also recommend a ratio of 1:1.64, with orientation ceasing to be critical when the resistance of the building envelope increases.

\section{Study Setting and Approach}

The study adopted a qualitative approach as it sought to explore the level of conformity of residential buildings to climatic responsive building design principles since very little research has been done on the subject matter in the region of study [32]. A three-stage process was adopted for the study. The first stage involved a diagnosis of thermal stress of the climate of Kumasi and identification 
of remedial actions and the evolution of bioclimatic design recommendations for the warm-humid climate of Kumasi using the Mahoney Tables. The second stage was an evaluation of the features of selected buildings in Kumasi to assess if they meet the recommendations spelt out in the first stage. The third stage involved an assessment of levels of satisfaction of a sampled number of occupants using their responses on indoor thermal comfort.

Kumasi, the study location, is the capital city of the Ashanti Region and is the second-largest city in Ghana. Kumasi is home to a major commercial and an industrial centre, with a huge timber processing community that serves the needs of people in Ghana. Kumasi is approximately 500 kilometres north of the equator and 200 kilometres north of the Gulf of Guinea.

\subsection{Study Buildings and Sources of Data}

Three sets of data were obtained to achieve the aim of the study. The first was climatic data comprising the monthly mean minima and maxima of air temperature, relative humidity and rainfall for Kumasi from the Ghana Meteorological Agency in Accra. The study also employed the observation of the features of selected study buildings from communities comprising four (4) each of Government-Owned Houses, Single Family Private Houses and Indigenous Compound Houses. The Indigenous Compound House and the Single-Family House types were selected to be studied because they constitute the largest proportions of housing types in Ghana with percentages of $51.5 \%$ and $28.7 \%$ respectively [33]. However, they are largely procured through the informal approach and not designed by professionals. The Government-Owned housing type was studied because their procurement is handled by building design professionals. The selection of the Indigenous Compound House and the Single-Family House types on one end compared to the Government-Owned housing type provides a basis to assess the level of compliance of buildings procured through informal and formal procurement approaches to the recommended bioclimatic design features of the region of study.

Features of the study buildings that were observed included their orientation, window openings and sizes, air movement patterns, wall thickness, shading devices and methods, and general arrangement and organisation of spaces, as done by [10]. The studied buildings have a varied number of bedrooms and supporting spaces. Table 2 presents the characteristics of buildings of study. The blocks are of single and two-storey heights and made of sandcrete blocks in a reinforced concrete post and beam frames, and sundried bricks. Some of the study buildings are shown in Figures 1-3. The buildings have various roofing systems; mono-pitch, double pitches and flat concrete roofs with parapet walls, which add to the external aesthetics. The average spacing between the various blocks is between 6 and 12 meters. Residents of the communities in which study buildings were selected formed the research population. The major data collection method used was questionnaires among a sample size of 50 occupants. The residents 
Table 2. Characteristics of buildings studied.

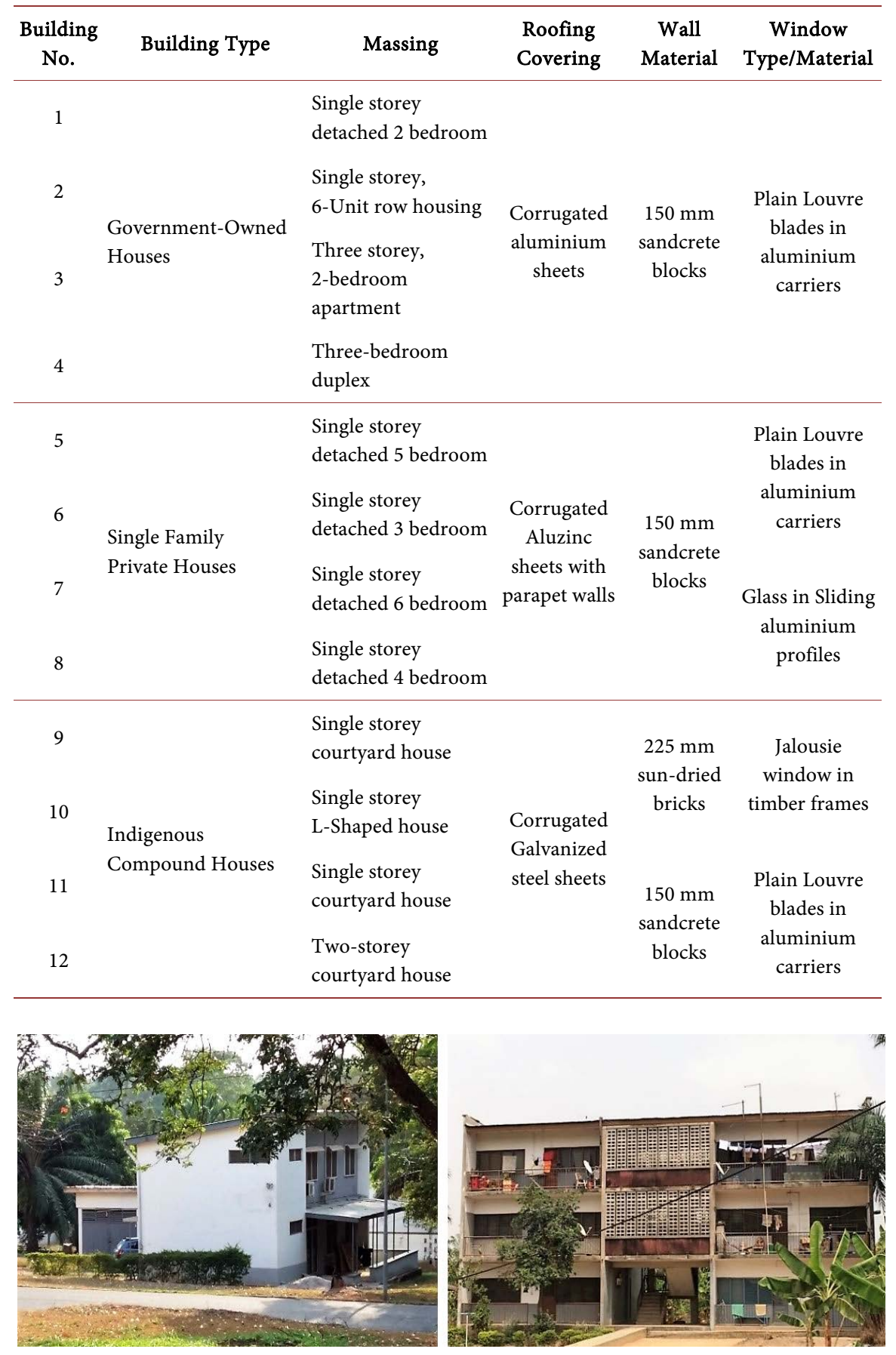

Figure 1. Exterior view of some government-owned houses.

rated their overall level of satisfaction with comfort levels by indicating the degree or extent by which they agreed or not on a scale.

\subsection{Analysis of Data}

The Mahoney Table was adopted to analyse the climatic data of Kumasi to evaluate the thermal stress imposed on the buildings. The procedures employed in 


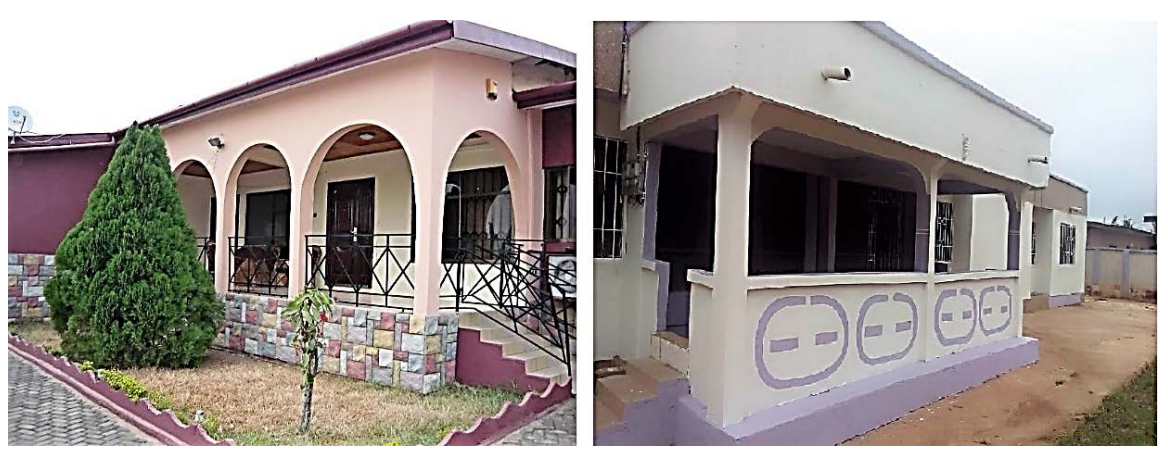

Figure 2. Front views of some single-family houses.
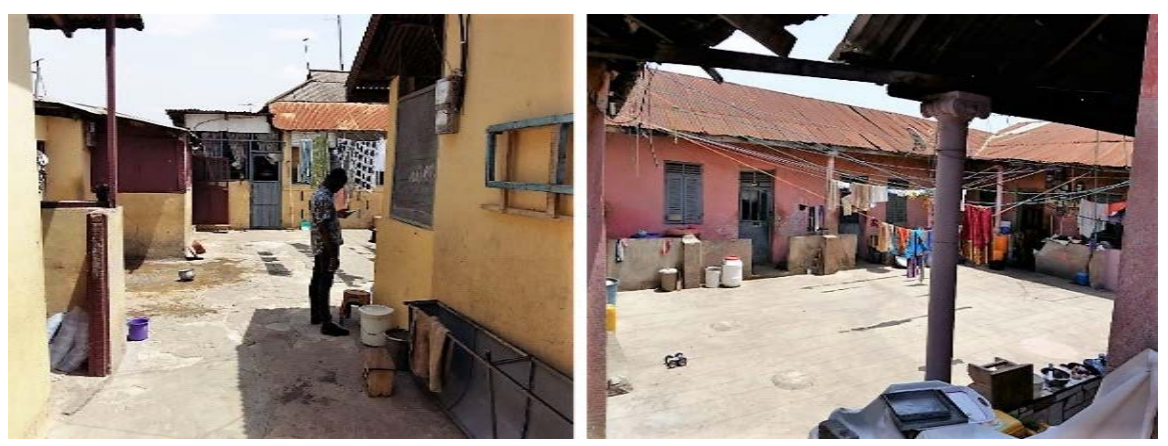

Figure 3. Views of a courtyard of some indigenous compound houses.

using of the Mahoney Tables are explained in detail in [12] [20] [34]. The Tables provided recommended design guidelines by using climatic data and simple calculations in sequence, starting with the basic and monthly available climatic data of temperature, humidity and rainfall as done by Eusebius [10], out of which a checklist was designed to collect data on bioclimatic design features of the study buildings for analysis. The bioclimatic design features are grouped under layout, spacing, air movement, size of openings, protection of openings, positions of openings, walls and floors, roofs, rain protection and outdoor sleeping and relaxation bioclimatic design features and analyzed within the context of the study objective. Data collected were converted into percentages and analysed using Microsoft Office Excel and the results were then summarized within the context of the study objectives.

\section{Results and Discussions}

The results of the study are presented and discussed in this section. They are organized in three segments: 1) The recommended bio-climatic design guidelines for climate-sensitive building designs for Kumasi; 2) The evaluation of the bio-climatic design features of the selected buildings typologies; and 3) Summary of residents' level of satisfaction with indoor comfort conditions.

\subsection{Bio-Climatic Design Guidelines for Climate-Responsive Building Design in Kumasi}

This section discusses the recommended bio-climatic design guidelines to 
achieve a climate responsive building design for the warm-humid climate of Kumasi. The specific recommendations are presented in Table 3 under layout, spacing, air movement, size of openings, the position of openings, protection of openings, walls and floors, roofs, outdoor sleeping and rain protection. For the climate of Kumasi, buildings should be rectangular shaped and oriented with the longer sides along the east-west axis orientation. With this orientation, the walls will receive less solar radiation in comparison to other orientations. This affirms [5] assertion that, direct sunlight must be excluded from the fenestration and window shades should be designed in such a way to cut off sun-rays.

Table 3. Recommended bio-climatic design guidelines for Kumasi from the Mahoney tables.

\begin{tabular}{|c|c|}
\hline 1. Layout: & 6. Protection of openings: \\
\hline long axis along an east-west orientation & shade to exclude direct sunlight \\
\hline rectangular-shaped buildings & deep verandas \\
\hline non-compact courtyards & wide overhangs \\
\hline 2. Spacing: & 7. Positions of openings: \\
\hline non-compact open spacing planning & windows in north and south walls \\
\hline protection from hot winds & windows at human body scale \\
\hline 3. Air movement: & 8. Roofs: \\
\hline single-banking rooms for cross ventilation & Light material \\
\hline permanent ventilation & reflective surface \\
\hline room height greater than $2.75 \mathrm{~m}$ & well-insulated roof with cavity \\
\hline 4. Size of openings: & 9. Rain protection: \\
\hline medium openings covering & protection from heavy rains needed \\
\hline $40 \%-80 \%$ of wall areas & adequate rainwater drainage \\
\hline avoiding openings in west walls & covered passageways \\
\hline 5. Walls and floors: & 10. Outdoor sleeping and relaxation: \\
\hline \multirow{3}{*}{$\begin{array}{l}\text { lightweight material } \\
\text { low thermal capacity }\end{array}$} & no provision for outdoor sleeping required \\
\hline & space on top of roofs \\
\hline & balconies or in patios \\
\hline
\end{tabular}

Another essential element that is required in all the twelve months of the year in the climatic condition of Kumasi is air movement. Air movement is imperative for continuous ventilation to promote efficient evaporation of moisture from the skin because of the prevalence of high relative humidity levels of the warm-humid conditions [20]. The need for continuous ventilation affects building design aspects such as the layout of the buildings, orientation, and the size and location of windows [35]. At the layout planning stage, buildings should be openly spaced and oriented to take advantage of the prevailing wind direction. Moreover, rooms should have a single-banking configuration with windows to maintain cross ventilation. Window and other openings should have a total area to achieve a window-to-wall ratio in the range of $25-40$ percent. All windows and openings should at best be in the northern and southern walls and placed at human body scale to ensure effective ventilation of occupants. They should have 
appropriate shading elements for protection from direct sun-rays.

Furthermore, in the warm-humid climate of Kumasi, the walls and roof should be constructed of lightweight materials that have low-thermal capacity. Adoption of cavity walls or composite walls may be very helpful in controlling the heat transfer from the outside to the inside of the building [36]. Thermal storage is not found to be essential for this region. This is supported in an earlier study by [28] that established that the warm-humid climate of Kumasi experiences diurnal temperature range of below $10^{\circ} \mathrm{C}$. Moreover, the roofs should have a reflective surface and be constructed with a cavity for insulation. The roofs of buildings should be designed with an adequate slope for easy runoff and rainwater drainage system to protect buildings from rain considering the intensity of rainfall recorded in this region.

\subsection{Evaluation of Bio-Climatic Design Features of Residential Building Typologies}

As specified in the recommended design guidelines for Kumasi, Eusebius [10] also recommends that all buildings should have an east-west axis orientation. Inferring from Table 4, about 67 per cent of the studied buildings conform to the recommended orientation for Kumasi, with the long sides of the buildings aligned to the east and west axis. The field observations revealed that the orientation for the other buildings was informed by factors such as the direction of slope, shape, access and the orientation of the land. Majority of the Single-family housing units are oriented with their entrance facades facing the access road and is found not to appropriate. However, at the community level, access roads to buildings happen to be aligned to the north-south axis and placed on either the eastern and western boundary of the site.

The recommended design guidelines also specify the adoption of rectangular shape for Kumasi to reduce the exposure of buildings to the sun. The single-family private houses have configurations with aspect ratios of close to $1: 1$ as shown in Figure 4. The observed configurations are not supported by [19] and [31] recommendations of having elongated buildings with an aspect ratio of between $1: 1.3$ to 2.0 for the tropics.

With respect to the placement of windows, all the studied buildings had openings placed within human body scale which fulfils the recommended design guidelines to foster physiological cooling. Even though the majority of the buildings studied had good orientation, about 70 percent of them had windows on the eastern and western walls in addition to that on the northern and southern walls. The four indigenous compound houses studied had a courtyard configuration with rooms on all four sides as shown in Figure 5, thus having openings exposed to the east and west. The placement of windows could be attributed to the inappropriate aspect ratio that was adopted for the design of the buildings. In spite of 70 per cent of the studied buildings having windows on the eastern and western walls and not conforming to the recommended position, no efforts are made to shade the windows as recommended by [21] and [23], thus leading 
Table 4. Bio-climatic design features of residential building typologies of Kumasi.

\begin{tabular}{|c|c|c|c|c|c|c|c|c|c|c|c|c|}
\hline Building No. & 1 & 2 & 3 & 4 & 5 & 6 & 7 & 8 & 9 & 10 & 11 & 12 \\
\hline Building Typology & \multicolumn{4}{|c|}{ Government Owned } & \multicolumn{4}{|c|}{ Single Family Private } & \multicolumn{4}{|c|}{ Indigenous Compound } \\
\hline \multicolumn{13}{|l|}{ Layout } \\
\hline East-west axis orientation & Yes & No & Yes & Yes & Yes & Yes & No & Yes & No & Yes & Yes & No \\
\hline Rectangular shape & Yes & Yes & Yes & Yes & Yes & Yes & Yes & Yes & Yes & Yes & Yes & Yes \\
\hline Use of courtyard & No & No & No & No & No & No & No & No & Yes & Yes & LS & Yes \\
\hline \multicolumn{13}{|l|}{ Spacing } \\
\hline Between Blocks (m) & NA & NA & NA & NA & 5.5 & 6.0 & 6.4 & 6.1 & 2.5 & 2.7 & 2.5 & 2.5 \\
\hline Overall height (m) & 2.9 & 3.2 & 9.1 & 6.5 & $<4.0$ & $<4.0$ & $<4.0$ & $<4.0$ & $<4.0$ & $<4.0$ & $<4.0$ & $<4.0$ \\
\hline \multicolumn{13}{|l|}{ Air Movement } \\
\hline Single-banked rooms & SB & DB & $\mathrm{DB}$ & SB & SB & $\mathrm{DB}$ & $\mathrm{DB}$ & SB & $\mathrm{SB}$ & $\mathrm{DB}$ & $\mathrm{DB}$ & SB \\
\hline Air-conditioned (some) & No & No & No & $\mathrm{AC}$ & No & No & No & No & No & No & No & No \\
\hline \multicolumn{13}{|l|}{ Size of Openings } \\
\hline Window-to floor ratio (\%) & 34.6 & 60.4 & 62.7 & 57.1 & 27.9 & 34.0 & 16.7 & 12.2 & 33.4 & 50.0 & 23.4 & 19.6 \\
\hline \multicolumn{13}{|l|}{ Positions of Openings } \\
\hline In North and South walls & Yes & No & Yes & Yes & No & Yes & Yes & Yes & Yes & Yes & Yes & Yes \\
\hline In west east walls & No & Yes & No & No & Yes & No & Yes & Yes & Yes & Yes & Yes & Yes \\
\hline Windows at human body scale & Yes & Yes & Yes & Yes & Yes & Yes & Yes & Yes & Yes & Yes & Yes & Yes \\
\hline \multicolumn{13}{|l|}{ Protection of Openings } \\
\hline Type of window width of overhangs & LV & LV & LV & LV & LV & SL & LV & SL & $\mathrm{JL}$ & LV & $\mathrm{JL}$ & LV \\
\hline \multicolumn{13}{|l|}{ Walls and Floors } \\
\hline External Walls (light weight) & SC & SC & SC & SC & SC & $\mathrm{SC}$ & SC & $\mathrm{SC}$ & SDB & SDB & SC & SC \\
\hline Internal Walls (light weight) & SC & SC & SC & SC & SC & $\mathrm{SC}$ & $\mathrm{SC}$ & $\mathrm{SC}$ & SDB & SDB & SC & SC \\
\hline Floors & $\mathrm{MC}$ & MC & $\mathrm{MC}$ & $\mathrm{MC}$ & $\mathrm{MC}$ & $\mathrm{MC}$ & $\mathrm{MC}$ & $\mathrm{MC}$ & $\mathrm{MC}$ & $\mathrm{MC}$ & MC & $\mathrm{MC}$ \\
\hline \multicolumn{13}{|l|}{ Roof } \\
\hline Roof Type & $\mathrm{AL}$ & $\mathrm{AL}$ & $\mathrm{AL}$ & $\mathrm{AL}$ & $\mathrm{AZ}$ & $\mathrm{AZ}$ & $\mathrm{AZ}$ & $\mathrm{AZ}$ & GL & GL & GL & GL \\
\hline Reflective and Light material & Yes & Yes & Yes & Yes & Yes & Yes & Yes & Yes & Yes & Yes & Yes & Yes \\
\hline Insulated/Ceiling & Yes & Yes & Yes & Yes & Yes & Yes & Yes & Yes & Yes & Yes & Yes & Yes \\
\hline Parapet & No & No & No & No & Yes & Yes & No & No & No & No & No & No \\
\hline \multicolumn{13}{|l|}{ Outdoor Sleeping } \\
\hline Foyer or patio & No & No & No & No & No & No & No & No & Yes & Yes & Yes & Yes \\
\hline Veranda & Yes & Yes & Yes & Yes & Yes & Yes & Yes & Yes & No & No & No & No \\
\hline Space on top of roofs & No & No & No & No & No & No & No & No & No & No & No & No \\
\hline \multicolumn{13}{|l|}{ Rain Protection } \\
\hline Covered passages & No & No & No & Yes & No & No & No & No & No & No & No & No \\
\hline Rain Gutter/Pipe & No & No & No & No & Yes & Yes & Yes & Yes & No & No & No & No \\
\hline
\end{tabular}

LEGEND: SB-Single Banking; DB-Double Banking; SDB-225 Sun-Dried Bricks; SC-150 mm Sandcrete Blocks; MC-Mass Concrete Slab; AC-Air-Conditioning; LV-Louvre Blades Window; JL-Jalousie Window; SL-Sliding Window; AL-Aluminum Roofing; Az-Aluzinc Roofing; Gl-Galvanized Roofing. 

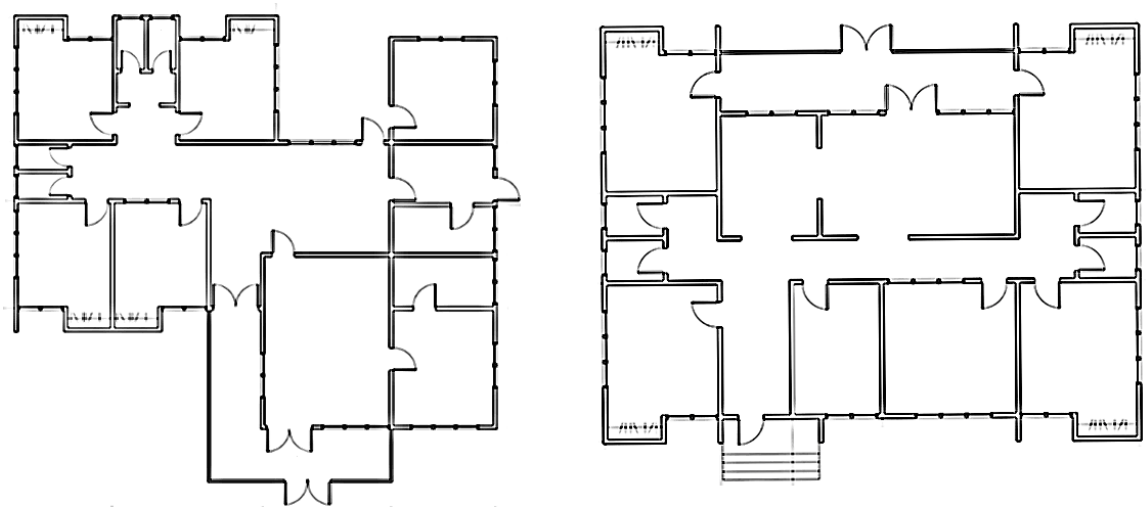

Figure 4. Ground floor plan of some single-family housing typology.

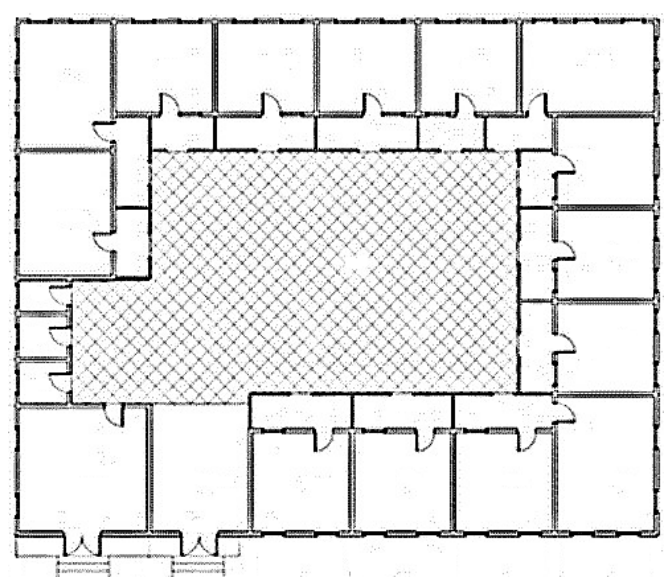

Figure 5. Ground floor plan of an indigenous compound housing typology.

to direct ingress of solar radiation. The government-owned houses, had their windows predominately placed in the northern and southern facing walls.

All the twelve (12) buildings studied conformed to the recommended design guidelines for Kumasi with respect to spacing of buildings to facilitate air movement. Nine of the buildings studied, representing 75 per cent had spacing ranging from 3 to 10 metres. This conforms to the minimum of 3 metre spacing from a building wall to the boundary of the site as stipulated by the National Building Regulations (LI 1630) of Ghana. Besides allowing free movement of air, this minimum distance will also facilitate the movement of fire tender in case of an emergency. None compliance to building regulations results in buildings being close to one another, thus hampering effective air distribution. Gut and Ackerknecht [15] further recommended the use of perforated walls for fencing in order not to impede air movement. From the results, it is observed that the single-family housing typologies resorted to the use of solid fencing as a means of security and demarcation of their property boundaries. The use of perforated walls for fencing could undermine privacy, besides associated security issues. The government-owned housing, however, has trees and shrubs defining their boundaries which do not completely impede air movement. 
About 60 percent of the buildings studied, largely the indigenous type, have a single-banking configuration with cross-ventilation as specified in the recommended guidelines for Kumasi, and 40 percent of the buildings have a double-banking configuration. The analysis revealed a trend where the single-family housing units, which are the most recent developments, have reduced window-to-wall ratios (Table 4). The derived recommended design guidelines specify window-to-wall ratio of 40 - 80 per cent for Kumasi. From Table 4, only 33 per cent buildings conformed to the recommendation, with 67 percent having ratios below the range. The buildings with window-to-wall ratios below the recommended range are largely among the single-family private housing typology. Interestingly such spaces have higher occupancy densities and the function of the spaces double as both sleeping and living areas, as observed by [37]. Moreover, the single-family private housing typology adopts the use of sliding windows systems fabricated with aluminium profiles. Adoption of sliding window profiles does not allow full utilization of the entire opening aperture to facilitate air movement [7], thus leading to poor ventilation of spaces. Respondents through the questionnaire claimed and attributed the small size of windows to the relatively high cost of the aluminium profiles.

Majority of the buildings studied had sandcrete blocks as the envelope material, as identified by [29] as being the most extensively used building material for building walls in the warm-humid climate. Sandcrete blocks are of a low thermal mass character which avoids overheating in response to relatively higher nighttime temperature and low diurnal temperature range of the region. Inferring from the evaluation made on roofs of the studied buildings, all the buildings studied conform to the recommendation with the buildings protected against rain by using roof with adequate pitches of roof in response to the relatively high intensity of rainfall recorded in the region.

\subsection{Level of Satisfaction of Residents with Indoor Comfort Conditions}

Overall, about $68 \%$ of the respondents complained about the experience of hot discomfort in their rooms during the day without the use of fans to aid in air movement. About 19 percent of the respondents mainly within the government-owned housing type rated ventilation levels in their spaces as good with the aid of fans. Thermal comfort conditions had very low percentages of 19 and 5.7 representing good and very good conditions respectively of mostly occupants in the recently built single-family private houses. About 50 percent of the respondents are of the view that the window sizes of their buildings are small when asked about their perception of the size of their window. Respondents indicated that, they mostly rely on fans throughout the day to achieve thermal comfort. According to [5] and [20], the use of fan provides an auxiliary system to obtain comfort through natural ventilation in tropical regions to enhance convective cooling and evaporation of moisture from the skin. 
About 54.3 percent of the respondents expressed general satisfaction with natural lighting levels in their homes. Respondents from the indigenous compound houses, largely expressed dissatisfaction with the level of natural lighting in their spaces during the day, without the use of supplementary artificial lighting. The poor lighting levels in their spaces could be attributed to low window-to-wall ratios as revealed in the field observations, poor reflectance of surfaces and use of curtains for privacy in spaces [38]. A lighting audit will need to be carried out to determine the appropriate lighting levels to ensure the visual comfort of occupants.

\subsection{Implications of the Findings}

The theoretical understanding of the bio-climatic design features for the warm-humid climates revealed by the study offers good knowledge that can inform education on climate responsive building design. Olotuah [39] captures the essence of this observation by asserting that architectural education, and by extension the practice of the profession, must not only be appreciative of the climate of a place, but must also be informed by it. Furthermore, the findings of the study provide a veritable platform for the application of climate responsive building design concepts. However, this is possible only if buildings are planned from the outset to counteract climatic extremes. The configurations of the buildings studied revealed that basic concepts such as aspect ratio, orientation, window-to-floor ratio, shading, among others were applied in the government-owned buildings that were designed by professionals, but were ignored in the single-family private house and indigenous compound house types, and show little effort at energy conservation.

Even though the study focused on three residential housing typologies in $\mathrm{Ku}$ masi, it would not be far-fetched for one to suggest that the design of the majority of buildings in Ghana do not adequately incorporate the recommended bio-climatic design features for the conditions of specific locations since many of the housing stock are currently being developed in the form of single-family private houses. Without adhering to the bio-climatic design principles in the design of buildings, as seen in the findings of the study, there will be the tendency for installation of mechanical cooling systems in the form of cooling and ventilation systems in buildings to improve thermal comfort conditions [40]. In developing countries such as Ghana where the majority of the populace cannot afford mechanical systems, occupants will have no option than to live in deplorable conditions. Among the bracket that can afford the use of air conditioners, awareness of the risks they pose towards a path to sustainability is low. Advocacy on enforcement of building regulations to adapt building design to climate conditions is encouraged to make it obligatory or provide motivation for building design professionals to apply acquired knowledge in the design of buildings.

Adopting climate responsive design approaches in the design of new buildings and retrofitting of existing ones should be treated as a fundamental component 
to the education of architectural students at an early stage in their education because of the ever-growing global concern for the use of conventional energy sources. Conventional energy sources (oil and gas) are finite and are associated with environmental consequences such as severe climate change due to global warming [2]. The design of a building should aim at achieving comfortable indoor conditions with meaningful or no use of energy, other than from renewable sources.

To facilitate the compliance of climate responsive building principles in the design of building, it is recommended that, the requirements on aspect ratio and orientation of buildings should be incorporated in the requirements for building permit acquisition process.

\section{Conclusions and Recommendations}

This study evaluated the bioclimatic design features of Government-Owned Houses, Single Family Private Houses and Indigenous Compound Houses and identified features that can enhance the environmental responsiveness of buildings in Kumasi, a city in the warm-humid climate of Ghana.

This study adopted the Mahoney Tables to undertake a climatic analysis to develop appropriate design guidelines for the climatic context. The developed design guidelines were then used to evaluate the bio-climatic design features of a sampled number of residential building types. The study revealed that features of the buildings reflect the recommended design guidelines, but to varied extents among the building typologies that were studied. This study has brought to fore the extent to which climatic responsive building design features may have been ignored in the design of family housing units in Ghana. Occupants generally find the conditions in such spaces unsatisfactory primarily as a result of the experience of hot discomfort in their spaces.

The findings are expected to engender a renewed interest in the design of buildings in response to prevailing climatic conditions to reduce reliance on energy use. This could provide a useful reference for contemporary architectural design practice and education in Ghana and regions of similar climatic conditions.

\section{Conflicts of Interest}

The authors declare no conflicts of interest regarding the publication of this paper.

\section{References}

[1] Ganem, C.A., Esteves, A. and Coch, H. (2006) Traditional Climate-Adapted Typologies as a Base for a New Contemporary Architectural Approach. PLEA2006 The 23rd Conference on Passive and Low Energy Architecture, Geneva, 6-8 September 2006.

[2] IPCC (2007) Climate Change 2007: Synthesis Report. Contribution of Working Groups I, II and III to the Fourth Assessment Report of the Intergovernmental Pan- 
el on Climate Change, IPCC, Geneva.

[3] Silva, G. and Guedes, M.C. (2006) Bioclimatic Architecture in East Timor-A Path to Sustainability. The 23rd Conference on Passive and Low Energy Architecture, Geneva, 6-8 September 2006.

[4] Schreckenbach, H. and Abankwa, J.G.K. (1982) Construction Technology for a Tropical Developing Country, GTZ.

[5] Givoni, B. (1982) Man, Climate and Architecture. Applied Science Publishers Limited, London.

[6] Owusu, S.E. (2001) Housing Supply and Demand in Kumasi. In: Adarkwa, K.K. and Post, J., Eds., Fate of the Tree: Planning and Managing the Development of Kumasi, Ghana, Woeli Publishing Services, Accra.

[7] Amos-Abanyie, S. (2011) Climate Change and Housing in Kumasi. In: Adarkwa, K.K., Ed., Future of the Tree-Towards Growth and Development of Kumasi, University Printing Press, Kumasi, 195-211.

[8] Babbu, A.H. and Anwar, M.F. (2016) Bio-Climatic Design Strategies for Buildings in Delhi, India. IJLTEMAS, 5, 1-7.

[9] Thirumaran, K. and Subhashini, S. (2014) Energy Efficient Passive Design Strategies for Buildings in Madurai. American Journal of Sustainable Cities and Society, 3, 184-202.

[10] Eusebius, U.C. (2011) Use of Mahoney Tables in Nigeria. Department of Architecture. Federal University of Technology, Akure.

[11] Khoshsima, E., Mahdavi, A., Rao, S.P. and Inangda, N. (2011) Learning from the Past: Case Study of Traditional Architecture of Southern Shores of Caspian Sea Region in Iran. International Journal of Applied Science and Technology, 1, 11.

[12] Koranteng, C., Amos-Abanyie, S. and Afram, S.O. (2015) An Evaluation of Climate Responsive Design Features of Buildings on KNUST Campus Based on Mahoney Tables. British Journal of Applied Science \& Technology, 10, 1-14. https://doi.org/10.9734/BJAST/2015/17795

[13] Wikner, E. (2009) Modelling Waste to Energy systems in Kumasi, Ghana. Committee of Tropical Ecology, Uppsala University, Uppsala.

[14] Neves, L. (2006) Architecture Integrated to Nature: The Use of Timber by Severiano Porto in Brazilian Amazon. PLEA2006 The 23rd Conference on Passive and Low Energy Architecture, Geneva, 6-8 September 2006.

[15] Gut, P. and Ackerknecht, D. (1993) Climate Responsive Building; Appropriate Building Construction in Tropical and Subtropical Regions. SKAT, St. Gallen.

[16] Lorraine, F. (2007) The Fundamentals of Architecture. AVA Publishing SA, Lausanne.

[17] Koenigsberger, O., Ingersoll, T.G., Mayhew, A. and Szokolay, S.V. (1975) Manual of Tropical Housing and Building. Orient Blackswan Private Limited, Hyderabad.

[18] Stauskis, G. (2014) Bioclimatic Principles in Architectural Design-A Way to Better Buildings. Vilnius Gediminas Technical University, Lithuani.

[19] Watson, D. and Labs, K. (1983) Climate Design: Energy Efficient Building Principles and Practices. McGraw-Hill, New York, 37.

[20] Raydan, D.K. and Melki, H.H. (2005) Climate and Comfort Passive Design Strategies for Lebanon. PLEA 2005 Conference Proceedings 1 and 2.

[21] Kamal, M.A. (2010) A Study on Shading Buildings as a Preventive Measure for Passive Cooling and Energy Conservation in Buildings. International Journal of Civil \& 
Environmental Engineering, 10, 19-22. http://www.ijens.org/102406-5252\%20IJCEE-IJENS.pdf

[22] Kamal, M.A. (2012) An Overview of Passive Cooling Techniques in Buildings: Design Concepts And Architectural Interventions. Acta Technica Napocensis: Civil Engineering \& Architecture, 55, 84-97.

[23] Maleki, B.A. (2011) Shading: Passive Cooling and Energy Conservation in Buildings. International Journal on "Technical and Physical Problems of Engineering" (IJTPE), 3, 72-79. http://www.iotpe.com

[24] Mostafa, A.M. (1989) Low Energy Cooling in Multi-Storey Buildings for Hot Arid Climates. Msc, The Massachusetts Institute of Technology, Cambridge.

[25] Walker, A. (2010) Natural Ventilation. The Whole Building Design Guide. http://www.wbdg.org/resources/naturalventilation.php

[26] Straube, J.F. (2001) Air Flow Control in Building Enclosures: More than Just Air Barriers. 8th Conference on Building Science and Technology, Toronto, 22-23 February 2001, 282-302.

[27] Straube, J.F. (2007) Air Flow Control in Buildings. Building Science Digest 014.

[28] Amos-Abanyie, S., Akuffo, F.O. and Kutin-Sanwu, V. (2013) Effects of Thermal Mass, Window Size, and Night-Time Ventilation on Peak Indoor Air Temperature in the Warm-Humid Climate of Ghana. The Scientific World Journal, 2013, Article ID: 621095. https://doi.org/10.1155/2013/621095

[29] Oppong, R.A. and Badu, E. (2012) Building Material Preferences in Warm-Humid and Hot-Dry Climates in Ghana. Journal of Science and Technology, 32, 22-37. https://doi.org/10.4314/just.v32i3.4

[30] Givoni, B. (1998) Climate Considerations in Building and Urban Design. Van Nostrand Reinhold, New York, 109.

[31] Szokolay, S.V. (2004) Introduction to Architectural Science: The Basis of Sustainable Design. Architectural Press, Oxford.

[32] Creswell, J.W. (2014) Research Design: Qualitative, Quantitative, and Mixed Method Approaches. 4th Edition, SAGE Publications, New York.

[33] GSS (2012) 2010 Population \& Housing Census: Summary Report of Final Results. Ghana Statistical Service.

[34] Xia, B. (2012) Research on the Mahoney Tables Used in Shanghai Building Energy Efficiency Design. In: Proceedings of International Conference on Low-Carbon Transportation and Logistics, and Green Buildings, Springer, Berlin, 769-774. http://link.springer.com/chapter/10.1007\%2F978-3-642-34651-4_104

[35] Hyde, R. (2000) Climate Responsive Design-A Study of Buildings in Moderate and Hot Humid Climates. E and FN Spon, London, 57.

[36] Mastouri, H., Bahi, H., Radoine, H. and Benhamou, B. (2020) Improving Energy Efficiency in Buildings: Review and Compiling. Materials Today. Proceedings, 27, 2999-3003. https://doi.org/10.1016/j.matpr.2020.03.270

[37] Afram, S.O. and Owusu, S.E. (2006) Design Innovations towards Enhancing the Quality of Living in Multi-Storey Compound Housing for Low-Income Households in Kumasi, Ghana. Journal of Science and Technology, 26, 76-87. https://doi.org/10.4314/just.v26i1.32965

[38] Koranteng, C., Simons, B. and Nkrumah, J. (2012) The Use of Natural Lighting in Students' Hostels: A Case Study of Ayeduase, a Suburb of Kumasi, Ghana. Journal of Science and Technology, 32, 38-48. https://doi.org/10.4314/just.v32i3.5 
[39] Olotuah, A.O. (2006) At the Crossroads of Architectural Education in Nigeria. CEBE Transactions, 3, 80-88. https://doi.org/10.11120/tran.2006.03020080

[40] Amos-Abanyie, S., Akuffo, F.O. and Quagrain, V. (2009) Unveiling Energy Saving Techniques for Cooling in Residential Buildings in Ghana. International Journal of Ventilation, 8, 23-35. https://doi.org/10.1080/14733315.2006.11683829 